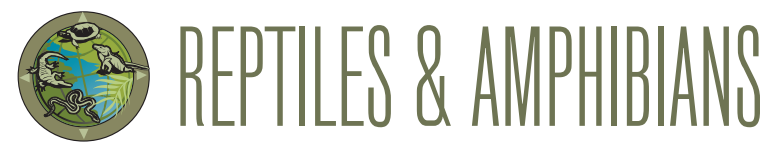

\title{
Male-to-male Combat in Andaman Island Grass Slkinks (Eutropis andamanensis) at Rangat, Andaman and Nicobar Islands, India
}

\author{
Nariman Vazifdar ${ }^{1}$, Monowar Alam Khalid ${ }^{2}$, and Amit Adhikari ${ }^{3}$ \\ ${ }^{1}$ Mumbai, Maharashtra, India (narimanvazifdar@gmail.com) \\ ${ }^{2}$ Integral University, Lucknow, Uttar Pradesh, India \\ ${ }^{3}$ Rangat, Andaman and Nicobar Islands, India
}

W hen two animals seek access to a commonly available limited resource, social conflict occurs (Parker 1974; Hand 1986). Both parties can benefit from settling social conflict without escalated fighting, as this can be costly in time and energy, can attract predators, and can result in injury or even death (Hand 1986; Gould and Gould 1989).

At approximately $1340 \mathrm{~h}$ on 30 May 2021, Amit Adhikari, a naturalist and avid wildlife photographer from Rangat, Andaman and Nicobar Islands, India, encountered two male Andaman Island Grass Skinks (Eutropis andamanensis) that were engaged in combat (Fig. 1). One lizard had managed to bite and hold the head and upper jaw of his opponent, while the latter had hold of the other's lower jaw. The interlocked lizards moved in circles in an apparent effort to gain an advantage on the other. This continued for 15 minutes until, disturbed by the human presence, they released their grip on each other and disappeared into the undergrowth. After 30 minutes, however, the skinks had returned to the same spot, resumed their fighting positions, and were interlocked again. This fight continued intermittenly for the next two days (observed and photographed from a distance), after which both skinks had sustained multiple injuries. Based on the consistent location, we believe that this was most likely a territorial dispute, which has been observed in many lizards (Doody et al. 2021).

Both skinks were similar in size; however, the male that appeared to be more dominant had bright orange dorsolateral patches, whereas the color of the patches was more subdued in the less dominant individual. In Australian Lined Rainbow Skinks (Carlia jarnoldae), a trend for dominants to have larger orange patches relative to body size than subordinates approached significance, suggesting that color-patch size could indicate dominance; however, orange patch size also might act as a long-distance visual cue to territory ownership and fighting ability, allowing individuals to avoid escalated conflicts by assessing each other from afar (Maclagan 2003). Whether color plays a similar role in $E$. andamanensis is unknown.
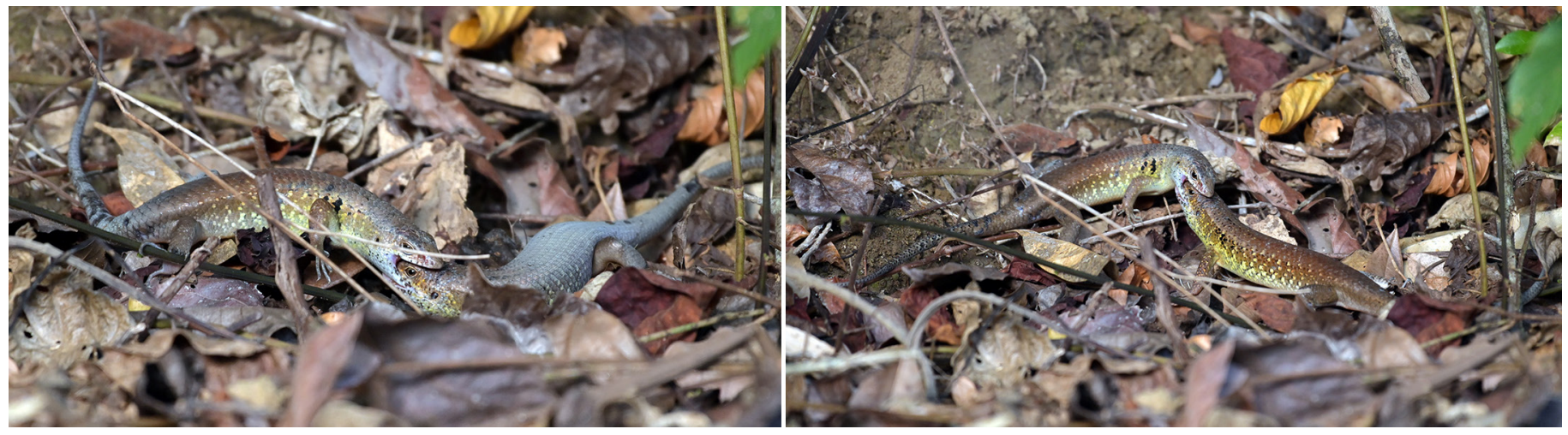

Fig. 1. Male-to-male combat between two Andaman Island Grass Skinks (Eutropis andamanensis) in Rangat, Andaman and Nicobar Islands, India. Photographs by Amit Adhikari. 


\section{Acknowledgements}

We thank the various people who encouraged us to write this note.

\section{Literature Cited}

Doody, J.S., V. Dinets, and G.M. Burghardt. 2021. The Secret Social Lives of Reptiles. Johns Hopkins University Press, Baltimore, Maryland, USA.

Gould, J.L. and C.G. Gould. 1989. Sexual Selection. W.H. Freeman \& Co., New York, New York, USA.
Hand, J.L. 1986. Resolution of social conflicts: dominance, egalitarianism, spheres of dominance and game theory. The Quarterly Review of Biology 61: 201-220. https://doi.org/10.1086/414899.

Maclagan, S. 2003. The establishment of dominance in male jewel skinks, Carlia jarnoldae: the roles of displays, body size and colouration. Unpublished Honours Thesis, School of Tropical Biology, James Cook University, Townsville, Queensland, Australia.

Parker, G.A. 1974. Assessment strategy and the evolution of fighting behaviour. Journal of Theoretical Biology 47: 223-243. https://doi.org/10.1016/00225193(74)90111-8. 